\title{
Sex Education Gaps in University Curriculum
}

Mohammad Amini (PhD)

Associate Professor, Department of Education, Faculty Member, University of Kashan, Iran.

Hamid Rahimi (PhD) Assistant Professor, Department of Education, Faculty Member, University of Kashan, Iran.

Zahra Rasooli (MA)

Field of Curriculum, Department of Education, University of Kashan, Iran.

\section{Corresponding Author:} Mohammad Amini

E.mail: amini2740@yahoo.com

Tell: 09133617139

Address: Department of Education, Faculty Member, University of Kashan, Iran.

Received: 22 Nov 2015

Revised: 12 Mar 2016

Accepted:17Apr 2016
Background: Sex education is one of the challenging areas of educational systems that has always been accompanied by many problems due to some obstacles and constraints. This has led to occurrence of many behavioral problems and deviations. The aim of this study was to determine the sex education gaps in university curriculum from the students' perspective.

Methods: This was a descriptive-survey on students of universities in Kashan (15235 students), during academic year 2013-14. Overall, 220 students were enrolled in this study using stratified random sampling. Data collection tool was a questionnaire of sex education with 28 questions and six components (objectives, content, procedures, experiences and learning opportunities, cultural and advisory institutions' performance and university atmosphere) using a 5-point Likert scale. The content validity was confirmed by experts. The reliability was estimated as 0.89 using Cronbach's alpha coefficient. Descriptive and inferential statistics were used to analyze the obtained data.

Results: The mean level of sex education gaps $(3.97 \pm 0.56)$ in the university curriculum was above the average (3). The highest mean was related to the component of procedures $(4.1 \pm 0.63)$ and experiences and learning opportunities $(4.1 \pm 1.01)$.

Conclusion: The results showed that the average level of gaps in sex education in the university curriculum is higher than the assumed mean level. The gaps are present in all components of objectives, content, procedures, experiences and learning opportunities, cultural and advisory institutions' performance and the university atmosphere.

Keywords: Sex Education, Students, University 


\section{Introduction}

Sex education as one of the key areas of education and upbringing along with other aspects such as social and mental-emotional training, play an important role in formation of personality, thoughts, emotions and behaviors of humans (1). However, sex education is also important from the perspective of sexual health. Sexual health training should be one of the most important components of healthcare, because many sexual problems are caused by the lack of knowledge about sexual issues. In addition, due to the spread of diseases, sexual disorders and increasing rates of AIDS, sex education and preventive programs are necessary (2).

Sexual health is a condition in which a person beneficiate from a healthy, appropriate and normal sexual relationship with desirable physical, emotional and behavioral excitement resulted from a certain harmony, intimacy, love and in other words sexual satisfaction. Undoubtedly, one of the most important ways to achieve this type of health is to provide necessary training for individuals (3).

Sex education affects health behaviors and leads to better understanding of sexual issues. Moreover, the variety of media and information and communication technology provides fast access to various forms of sexrelated information. This technical feature practically makes it easy for young individuals to retrieve and use different sexual contents and images for personal use (4). Obviously, the lack of proper and timely sex education can make the learners vulnerable to perform a variety of risky behaviors. On the other hand, one must also accept the fact that sexual behavior are acquired and largely based on learning, and requires special trainings and education. Since educational institutions have the greatest impact on sex education after the family, and many parents consider conversations about sex as indecent and misbehavior, it is necessary to integrate sex education and its related information in form of a codified and correct curriculum, which is gradually presented according to the phases of growth (1). From the perspective of Romiro (2011), gender and its related issues are so severe and risky in most countries that requires research interventions, especially educational research and training (5). Smith (2008) suggested that sexual training indicates a controversial topic that is a primary matter of discussion in today's society, but adoption of more proactive approach by the educational centers is required in this regard (6). On emphasizing the role of sex education and training, House (2010) believes that the existence and implementation of an educational approach leads to long-term behavior change and gaining healthy emotions, thoughts and social attitudes (7). From the perspective of Santrock (2010), sex education is a permanent process through which individuals acquire the necessary information about sex. This process helps individuals to a healthy sexual development, healthy and satisfactory marital relationships and successful playing of sexual roles. The purpose of sex education is to create healthy sexual behaviors and eliminate unhealthy sexual behaviors (8). Sex education tries to provide the necessary conditions for creating and developing healthy sexual behavior away from any extremes, by emphasizing on goals and targets such as guiding and instructing learners on how to behave toward the opposite sex, cognitive and logical awareness and information acquisition, preventing problems and sexual dissatisfactions, creating healthy attitudes, mental health development, social adaptation and coping with behavioral disorders $(2,9,10)$.

In this regard, preparation and development of a set of contents, learning-related experiences and its accurate scientific presentation by educational centers provide the practical background necessary to achieve the objectives of sex education and the acquisition of knowledge and essential skills (11). Vivancos (2013) concluded that learning about sex-related issues in educational centers result in reduced risk of unprotected sex and sexually transmitted disease (STD)(12). Study of Silva (2013) in Brazil shows that authorities and officials of education consider sex education as a matter of priority and every teacher is required to prepare a training plan to integrate sex education topics in their teaching (13). Study of Aresu (2013) indicated that sex education has been 
seriously considered in China due to its growing importance in education system since the late 1980s (14). The results of Gursimsek (2012) on sex-related issues showed that designing an educational course in this regard has a positive impact on teachers' attitudes toward sexual matters (15). Lindberg (2012) concluded that sex education can provide the necessary background to avoid premature sexual relationships. The effect of sex education is not limited to sexual relationships, but spreads to contraception issues, reproductive health and partner selection (16). Woo (2011) concluded that although most teachers integrate forms of sex education in their curriculum, only half of them implement a comprehensive curriculum of sex education. In this context, personal values of the instructor and his/her resources play an important role in the curriculum's content (17).

Kirby's (2006) meta-analysis of 83 studies on the effects of sex education programs in different countries indicated the success of most these programs. In fact, these programs corrected sexual misconducts and reduced risky sexual behaviors. The effective sex education programs in the field of sex education have defined goals, appropriate teaching methods and appropriate enforcement mechanisms (18). Hua- Lou (2006) study considered the capacity of the Internet for sex education and emphasized on using Internet tools by education centers to increase the level of sexual knowledge, sexual health and attitude change in students (19). Reis (2011) study on the effects of sex education on health and reproductive health promotion of university students in Portugal showed that most students have healthy, appropriate and constructive sexual attitudes, and at the same time there is a positive association between receiving trainings and sex education with avoiding risky sexual behaviors and relevant knowledge and skills acquisition (20). Khodadadi (2009) reported the lack of sex education and sexual morality in the university curriculum and considered lack of proper education as the reason for misguidance among students. The serious necessity of sex education in the curriculum and its delivery as an official curriculum was also emphasized (21).

Amirian zadeh (2007) indicated the position and necessity of sex education in aspects such as prevention of cultural invasion, sexual conduct, maintaining chastity, preventing sexual violation, having a healthy society, readiness to start a family and mental health, and emphasized on the need for incorporation of a lesson titled "Sex Education". However, the mentioned author believes that this is not highlighted in the current Iranian educational system. With the help of topics that Islam has risen in relation to the sex education and training, a lesson titled "Sex education from the perspective of Islam" could be planned for each course separately, from preschool to higher education levels (22). Mohamadi asserted that sex education in Islam has addressed all aspects of the issue from sexual health to how to strengthen man-woman relationship in the family. By correct utilization of this education system and designing an appropriate curriculum based on it, an efficient sex education system can be developed (23). Farmahini study (2005) indicated the need for sex education by describing ways to control and modify the sexual instinct, explanation of puberty hygiene, effects of friends on health or downfall of an individuals, sexual morality and knowledge of students about the dangers of STDs from the perspective of students, parents and secondary school teachers (1).

Nevertheless, it should be mentioned that the success and effectiveness of any educational system in the context of sex education may provide the necessary basis for prevention and dealing with all sorts of physical and mentalpsychological disorders, social and cultural deviations and anomalies. Moreover, it saves costs in many aspects that are used on an annual basis and in different ways by the government and its affiliated entities to fight various social and cultural deviations and anomalies. Using such approach to investigate and identify deficiencies and gaps in implemented official curricula by various universities and centers of higher education in the field of sex education, can provide a clear and documented image of current realities and provide necessary intellectual and practical 
backgrounds for accurate and scientific decision-making in this area.

Based on the above theoretical and empirical foundations, this study aimed to investigate and evaluate the gaps in sex education in the curriculum of the universities of Kashan, in addition to determining the difference and extent of students' attitudes about sex education gaps in terms of demographic characteristics.

\section{Methods}

This Study was a descriptive-survey on all university students (15235 individuals) in Kashan (University of Kashan, Kashan University of Medical Sciences and Azad University of Kashan) during 2013-14. Overall, 220 individuals were selected as subjects. Since the population variance was unknown, a pilot study on 30 students (10 from each university) was conducted and questionnaires were distributed among them. After extracting the data related to the answers of each group, the variance was estimated as 0.15 , with population size of 15235 and the error of 0.05 . The sample size of the study was determined as 227 individuals using the Cochrane formula by stratified random sampling. Based on that, 93 individuals were selected from the University of Kashan (6602), 89 students from the University of Medical Sciences (2635) and 40 students from the Azad University (5998) as study samples.

In this study, 220 questionnaires were collected. Given that the collected rate of questionnaires was 0.97, statistical analysis was performed on 220 subjects and statistical power, significance level and adequacy of 0.97 was estimated after a preliminary analysis.

Data collection tool was a constructed questionnaire of sex education. The questionnaire's questions were extracted based on the literature and specialized tests related to sex education in form of main elements of curriculum from documents, books and journals. The questionnaire was designed in form of 30 questions, which were reduced to 28 after the pilot study and determination of the validity and reliability. The questionnaire included 28 questions and six components of objectives (5 questions), content (5 questions), procedure (5 questions), experiences and learning opportunities (4 questions), cultural and advisory institutions' performance (5 questions) and the university atmosphere (4 questions), scored based on a five-point Likert scale ( 1 = strongly disagree, 2 = disagree, $3=$ neutral, $4=$ agree and strongly agree $=5$ ). In this scale, respondents express their understanding of different categories from 1 to 5 . Since the scale of the questionnaire was five points, the assumed mean (3) was used for the analysis, so that the obtained mean of above (3) reflected more gaps and mean lower than (3) represented less gaps in the field of sex education. Content validity was confirmed by experts and professors. Overall reliability was determined as 0.89 by Cronbach's alpha coefficient and reliability for each item was as follows: 0.79 For objectives , 0.66 for content , 0.77 for procedure , 0.78 for experiences and learning opportunities, 0.71 for cultural and advisory institutions' performance and 0.6 for the university atmosphere (0.6). These were at significance level of $\mathrm{P}=0.001$ and indicated the high reliability of the assessment tool. After obtaining the necessary permissions from the authorities of Kashan University of Medical Sciences, University of Kashan and Azad University, written consent was obtained from all the participants. They were also assured that the questionnaire will be anonymous, results will remain confidential and later handed to them at the end the project. Sufficient time was considered for filling out the questionnaire. After giving these explanations, the researcher distributed the questionnaires and collected completed versions within three weeks. Data analysis was done at descriptive level (frequency, percentage, mean and standard deviation-SD) and inferential level (one sample t-test and analysis of variance) using SPSS-18 software. Statistical significance level was considered at $\mathrm{P}<0.05$. The limitations of this study were solely using self-report questionnaires for assessment of variables, limitation of the samples to the Universities in Kashan and cross-sectional data collection.

\section{Results}

Based on the findings, $69.5 \%$ of the subjects were females, $85 \%$ were single, $78 \%$ were 
BSc students and $22 \%$ were MSc students. In addition, $43 \%$ of the subjects were from the University of Kashan, $17.5 \%$ were from the University of Medical Sciences and 5.17\% were from the Azad University. Assumption of normality was done through KolmogorovSmirnov test and Shapiro test. Normality of the data were confirmed in both KolmogorovSmirnov test $(\mathrm{P}=0.1, \mathrm{x}=1.2)$ and Shapiro test $(\mathrm{P}=0.09, \mathrm{x}=1.28)$ at 0.05 error-level.
The findings of this study showed that the mean level of gaps in sex education components at universities of Kashan is higher than the average level (3). The highest mean was recorded for the component of procedures $(4.16 \pm 0.64)$ and experiences and learning opportunities (4.14 \pm 1.17). According to the results, the highest gaps were related to the components of procedures and experiences and learning opportunities (Table 1).

Table1: One sample t-test: Comparison of mean levels of sex education gaps with assumed mean of (3)

\begin{tabular}{cccccc}
\hline Variable & Number & Mean \pm SD & t & P-value & Confidence interval \\
\hline Objectives & 220 & $3.95 \pm 0.72$ & 19.96 & 0.0001 & $0.86-1.05$ \\
Content & 220 & $3.57 \pm 0.77$ & 10.9 & 0.0001 & $0.47-0.67$ \\
$\begin{array}{c}\text { Procedure } \\
\text { Experiences and learning }\end{array}$ & 220 & $4.16 \pm 0.64$ & 26.9 & 0.0001 & $1.24-1.07$ \\
$\begin{array}{c}\text { opportunities } \\
\text { Performance of cultural }\end{array}$ & 220 & $4.14 \pm 1.17$ & 16.7 & 0.0001 & $0.98-1.29$ \\
$\begin{array}{c}\text { institutions } \\
\text { University atmosphere }\end{array}$ & 220 & $4.00 \pm 0.69$ & 21.5 & 0.0001 & $0.90-1.089$ \\
$\quad$ Sex education & 220 & $3.99 \pm 1.04$ & 14.07 & 0.0001 & $0.85-1.13$ \\
\hline
\end{tabular}

One sample t-test at significance level of $\mathrm{P}<0.05$

The study showed no significant difference in the students' view on sex education gaps based on gender, marital status and educational level. In other words, male and female, single and married and undergraduate and postgraduate students had the same attitude toward sex education gaps (Table 2). There was no statistically significant difference found between views of students at different universities of Kashan regarding the gaps in sex education (Table 3).

Table2: Independent t-test for the comparison of mean of sex education in terms of gender, marital status and educational level

\begin{tabular}{cccccc}
\hline \multicolumn{2}{c}{ Variable } & Number & Mean \pm SD & $\mathrm{t}$ & P-value \\
\hline \multirow{2}{*}{ Gender } & Female & 153 & $3.9 \pm 0.60$ & \multirow{2}{*}{0.45} & 0.65 \\
& Male & 67 & $3.9 \pm 0.40$ & & 0.38 \\
Marital status & Single & 187 & $3.9 \pm 0.55$ & 0.86 & 0.38 \\
& Married & 33 & $3.8 \pm 0.58$ & & \\
Education & Bachelor & 171 & $3.9 \pm 0.57$ & -0.11 & 0.92 \\
level & Master & 49 & $3.9 \pm 0.56$ & & \\
\hline
\end{tabular}

Table 3: Comparison of the mean of sex education components in terms of the university

\begin{tabular}{cccccc}
\hline & Variable & Number & Mean \pm SD & F & P-value \\
\hline \multirow{4}{*}{ University } & Kashan & 95 & $3.8 \pm 0.50$ & & \\
& Medical Sciences & 38 & $3.8 \pm 0.68$ & & \\
& Azad & 87 & $3.8 \pm 0.55$ & 0.01 & 0.98 \\
& Total & 220 & $3.8 \pm 0.55$ & & \\
\hline
\end{tabular}


In terms of the year of entry, students from the entry year 2011 expressed significantly higher gaps in the field of sex education compared to the views of other students. Post hoc tests showed the greatest difference between the entry year 2010 and 2011 compared with other students. There was no statistically significant difference found between entry year 2012 and 2013 (Table 4).

Table 4: Comparison of mean of sex education components in terms of entry year

\begin{tabular}{cccccc}
\hline Variable & & Number & Mean \pm SD & F & P-value \\
\hline \multirow{6}{*}{ Entry Year } & 89 & 70 & $4.06 \pm 0.58$ & & \\
& 90 & 37 & $4.10 \pm 0.53$ & & \\
& 91 & 65 & $3.8 \pm 0.52$ & 3.26 & 0.022 \\
& 92 & 48 & $3.94 \pm 0.57$ & & \\
& Total & 220 & $3.96 \pm 0.56$ & & \\
\hline
\end{tabular}

\section{Discussion}

The results showed that the mean of gaps in sex education at universities is at levels higher than average. These gaps were in the components of objectives, content, procedures, experiences and learning opportunities, cultural and advisory institutions' performance and the university atmosphere. The results regarding the component of objectives showed that educational programs and curriculum of universities do not have clear and concise objectives and policies in the field of sex education for students and evaluating their issue and problems in this area. Sex education tries to provide the necessary conditions for creation and growth of healthy sexual behavior away from any extremes, by emphasizing on goals and objectives such as guidance and instruction on behavior towards the opposite sex, acquisition of information, cognitive and logical knowledge, preventing sexual problems and dissatisfaction, creating a healthy attitude, development of mental health and social adaptation and dealing with behavioral disorders $(4,9,10)$.

The results of the present study are in agreement with the results of Amirian zadeh (2007) that found that the status and necessity of sex education in Iranian educational system is not strong (22). In the aspect of content, the results suggested that many students are faced with major lack of correct sexual awareness. Thus, educational contents in universities do not provide sufficient information for recognition and acquiring a proper sexual identity, the risks and negative effects of STDs, features and criteria of a successful marriage and a good spouse, appropriate ways to control sexual instinct and risky ways for its satisfaction to students. In regards to the methods of implementation, it is certain that no clear methods are defined in universities and no one is aware of such procedures. In fact, the methods and approaches of implementation by universities emphasize on maintaining the students' sexual issues "enclosed". Basically, no scientific methods are used for sex education of students in the university and if some methods are there to provide sex education for students, they are stereotyped, passive and superficial. Khodadadi (2009) demonstrated the gaps of sex education and sexual morality in curriculum, indicating the lack of proper education as the reason for the young individuals' misguide, and suggested the necessity of incorporating sex education in the curriculum and its delivery in form of an official curriculum (21).

In relation to the component of experiences and learning opportunities, the lack of specialized meetings with the presence of physicians, psychiatrists and psychologists in the field of scientific investigation of issues and young people's sexual problems is evident. In addition, holding meetings and special sessions with the presence of clerics in the field of sex education and sexual health are not taken seriously. On the other hand, "training packages" that give the necessary information in the field of sex education and sexual health do not exist. Silva (2013) suggested that the authorities and directors of education should consider sex education as a matter of priority, and every teacher should 
offer a training program for integration of sex education with his/her teaching topics (13). In relation to the component of cultural and advisory institutions' performance, the public and cultural departments of universities do not take certain actions for proper, and these institutions do not pay much attention to timely sex education of students and specialized scientific assessment of students' sexual problems. The university counseling office has no specific program for students' sex education. Moreover, meetings are not held for students in places such as dormitories to discuss experiences and sexual issues. On the other hand, no extracurricular activities and notification are performed on special occasions at universities. In relation to the component of the university atmosphere, the dominant culture and values of the universities prevent and forbid the discussions related to sex education. Because of this atmosphere and some misunderstandings, students try not to discuss sexual topics at the university and acquire their sexual awareness from informal methods and outside the experiences gained at the university. Results showed that the mean of gaps in the field of sex education from the perspective of male and female, married and single and undergraduate and postgraduate students are equal. These results are in agreement with the study of Khamsei (2006) (24) and inconsistent with study of Amini and Tamannayi (2011). Khamsei (2006) found no significant difference in the overall score of sexual behavior between male and female students (22). Amini (2011) found no significant difference between the perspective of male and female students in the field of sex education (25). Results showed no significant difference between the perspectives of students at universities of Kashan on sex education gaps. The mean level of sex education gaps from the perspective of students from the 2011 entry was significantly higher in comparison with other students. This indicates that the gaps in sex education are more considered by this group of students.

\section{Conclusion}

The results showed that the mean level of sex education gaps in the universities' curriculum is higher than the assumed mean, from the perspective of students. This shows that gaps exist in relation to all components of objectives, content, procedures, experiences and learning opportunities, cultural and advisory institutions performance and university atmosphere. Given the presence of these gaps and their role in reducing many problems and behavioral deviations, universities' curricula are required to have clear formulated goals and policies in the field of sex education and this education should be considered by the universities as an official action and program. The content of sex education in the higher education level should include items such as the correct awareness about sex, appropriate acquisition of sexual identity, the risks and negative effects of STDs (AIDS, syphilis, gonorrhea, etc.), proper methods to control sexual instinct and risky practices for its satisfaction, the criteria for a successful marriage and finding a good spouse and trainings for students in these regards. In addition, it is necessary for universities to prepare defined procedures and appropriate sex education and provide necessary knowledge in this field. Given that the enclosed approach does not solve the problems of students about sexual issues, scientific methods of sex education are necessary for students to replace passive methods and superficial techniques. Specialized meetings with the presence of physicians, psychiatrists, psychologists and clerics for the scientific evaluation of students' sexual issues and problems should be held. On the other hand, training packages including books, pamphlets, educational CDs that provide the necessary information on sexual health, should be developed and provided for the students. Moreover, the student counseling office should design and implement the necessary programs in the field. It is important that the atmosphere of the higher education system should be organized in such a way that causes no misunderstandings or sensitivity about sex education and discussions about sexual issues, so that students could acquire the knowledge and sexual awareness through official methods and from their experience at the university. 


\section{Acknowledgements}

This article was derived from a Master's thesis in the field of curriculum planning with the number 136470 (2013) at the Faculty of Social Sciences, University of Kashan. The

\section{References}

1. Farmahini M. appropriate content for sex education in schools, Journal of Islamic Education, 2005; 3, 8: 15-33. [In Persian]

2. Hasanzadeh R. the effect of sex education on family health, 2ed National Conference in Family Pathology in Iran, Tehran: University of Shahid Beheshti. 2004. [In Persian]

3. Olson D. Circumcises model of marital and family systems. The association for family therapy Philadelphia: Black well: 2010; 32(6): 53-68.

4. Doran B. public medias and sex affaires, Conference on Family and Sex Problem, Tehran: University of Shahed. 2007. [In Persian]

5. Ramiro L. Educação sexual, conhecimentos, crenças, atitudes e comportamentos nos adolescentes. Revista Portuguesa de Saúde Pública, 2011; 29 (1):11-21.

6. Smith T. Development and validation of the sex education confidence scale (SECS), J Education \& Human Development, 2008; 2 (2): 53-62.

7. House L. Competence as a predictor of sexual and reproductive health outcomes for youth: A systematic review. J Adolescent Health, 2010; 46(3), 7-22.

8. Santrock JW. Life-span development. Mc GrawHill. 2010.

9. Cort EM. an initial exploration of community mental health nurses attitudes to and experience of sexualityrelated issues in their work whit people experiencing mental health problems, J Psychiatric and Mental Health Nursing. 2001; 8(6): 489-99.

10. Nasiri Y. Pathology of sex education base on views of teachers in middle schools, thesis MA, University of Isfahan, 2003. [In Persian]

11. Davaei M. sex education in Islam, 2ed National Conference in Family and Sex Problem, Tehran: University of Tehran. 2004. [In Persian]

12. Vivancos R. School-based sex education is associated with reduced risky sexual behavior and sexually transmitted infections in young adults. Public Health. 2013, 127, 1, 53-7.

13. Silva DQ. Sex education in the eyes of primary school teachers in Novo Hamburg, Rio Grande do Sul, Brazil.Reproductive Health Matters.2013; 21,41:11423. authors would like to thank all the managers and students at the University of Kashan, Kashan University of Medical Sciences and Azad University of Kashan who helped us in this study.

14. Aresu A. Sex education in modern and contemporary China: interrupted debates across the last century. International Journal of Educational Developments. 2013; 29 (5): 532- 41.

15. Gursimsek I. Does sexuality education effect teacher candidates, attitudes about sexuality and homosexuality Proscenia- Social and Behavioral Sciences, 2012; 1(1): 980- 83.

16. Lindberg LD. Consequences of sex education on teen and young adult sexual behaviors and outcomes. $\mathrm{J}$ Adolescent Health. 2012; 51,4: 332-38.

17. Woo GW. Factors affecting sex education in the school system. Journal of Pediatric and Adolescent Gynecology. 2011; 24. 3: 142-46.

18. Kirby D. Sex and HIV education programs: their impact on sexual behaviors of young people throughout the world. J Adolescent Health, 2006; 40 (3): 206-17.

19. Hua- Lou C. Can the internet be used effectively to provide sex education to young people in China? Journal of Adolescent Health, 2006; 39 (5):720-28.

20. Reis M. The effects of sex education in promoting sexual and reproductive health in Portuguese university students, International Conference on Education and Educational Psychology, Portugal: Institute of Hygiene and Tropical Medicine, 2010.

21. Khodadadi M. sex education components, 4th National Conference in Family and sex Health, Tehran: University of Shahed. 2009. [In Persian]

22. Amirian zadeh M. the situation of sex education in schools and higher education, 3ed National Conference in Family and sex Health,Tehran: University of Shahed. 2007. [In Persian]

21. Mohamadi $H$. the study of sex education foundation and principals base on Islamic view, Thesis MA, University of Shahed. 2007. [In Persian]

24. Khamsei A. the study of relationship sex behavior and sex role designs in students, Family Researches, 2006; 2, 8: 51-65. [In Persian]

25. Amini M., \& Tamanaeifar M. sexual education in high school curriculum, Curriculum Researches, 2011, 1, 1: 170-201. [In Persian] 